\title{
Arthropod-borne viruses transmitted by Phlebotomine sandflies in Europe: a review
}

J Depaquit (jerome.depaquit@univ-reims.fr)'1, M Grandadam²,3, F Fouque ${ }^{4}$, PE Andry1, C Peyrefitte

1. Université de Reims Champagne Ardenne, AFSSA, JE 2533-USC “VECPAR", Reims, France

2. Laboratoire associé au Centre national de référence des arbovirus, Unité de virologie tropicale, Institut de médecine tropicale

du Service de santé des armées, Marseille, France

3. Centre national de référence des arbovirus, Institut Pasteur, Paris, France

4. Cellule d'Intervention Biologique d'Urgence (CIBU), Institut Pasteur, Paris, France

5. Unité de virologie, Département de Biologie des Agents transmissibles, Centre de Recherche du Service de Santé des Armées, Grenoble, France

Citation style for this article: Depaquit J, Grandadam M, Fouque F, Andry P, Peyrefitte C. Arthropod-borne viruses transmitted by Phlebotomine sandflies in Europe: a review. Euro Surveill. 2010;15(10):pii=19507. Available online: http://www.eurosurveillance.org/ViewArticle.aspx?Articleld=19507

Phlebotomine sandflies are known to transmit leishmaniases, bacteria and viruses that affect humans and animals in many countries worldwide. These sandfly-borne viruses are mainly the Phlebovirus, the Vesiculovirus and the Orbivirus. Some of these viruses are associated with outbreaks or human cases in the Mediterranean Europe. In this paper, the viruses transmitted by Phlebotomine sandflies in Europe (Toscana virus, Sicilian virus, sandfly fever Naples virus) are reviewed and their medical importance, geographical distribution, epidemiology and potential spreading discussed. Data on vertebrate reservoirs is sparse for sandfly fever viruses. The factor currently known to limit the spread of diseases is mainly the distribution areas of potential vectors. The distribution areas of the disease may not be restricted to the areas where they have been recorded but could be as wide as those of their vectors, that is to say Larroussius and $P$. papatasi mainly but not exclusively. Consequently, field work in form of viral isolation from sandflies and possible reservoirs as well as laboratory work to establish vectorial competence of colonised sandflies need to be encouraged in a near future, and epidemiological surveillance should be undertaken throughout the European Union.

\section{Introduction}

During the last decade, several cases of infections due to Toscana virus have been recorded in Europe (Italy, France, Spain, and Portugal). A few studies focusing on the viruses transmitted by Phlebotomine sandflies have been carried out. This review summarises the data related to arthropod-borne viruses transmitted by Phlebotomine sandflies in Europe.

Phlebotomine sandflies are the vectors of the Leishmania, pathogens that cause diseases called leishmaniases in more than 80 countries in the Old and New World. Sandflies are also vectors of other human pathogens such as Bartonella and viruses belonging to three different genera: (i) the Phlebovirus (family Bunyaviridae) including sandfly fever Sicilian virus, sandfly fever Naples virus, Toscana virus and Punta Toro virus; (ii) the Vesiculovirus (family Rhabdoviridae) including Chandipura virus [2-3] and (iii) the Orbivirus (family Reoviridae) including Changuinola virus [1]. The latter viruses have been associated with several outbreaks in humans. Further less important viruses have also been found in Europe. Chios virus was isolated from a human case of severe encephalitis (Papa and Pavlidou, personal communication) in Greece and additionally three other viruses were isolated from Phlebotomine sandflies: Corfou virus from Phlebotomus (Larroussius) neglectus, in Greece [4], Massilia virus from P. (L.) perniciosus, in France [5] and Arbia virus from P. (L.) perniciosus and from $P$. (L.) perfiliewi in Italy. However, so far there are no reports of human disease from these viruses.

Little is known about the viruses transmitted by Phlebotomine sandflies and they can be, to our opinion, considered as neglected pathogens. However, the Toscana virus, sandfly fever Naples and Sicilian viruses are endemic in the Mediterranean region and could spread to more temperate areas in Europe where vectors are abundant. Moreover, other viruses transmitted by sandflies and circulating in India may be imported into Europe by introduction of viremic patients emphasising the need to consider these viruses relevant from a European public health perspective.

\section{Clinical picture and geographical distribution \\ Sandfly fever Sicilian and Naples virus infections}

Sandfly fever Sicilian and Naples virus and other related viruses cause the "three-day fever" or "papatacci fever". Patients present with influenza-like symptoms including fever, retro-orbital pain, myalgia and malaise and usually recover fully within a week. 
However, infections with sandfly fever Naples and Sicilian viruses, even when mild, have shown to be highly incapacitating for the time patients are affected.

The human cases and some virus isolation from sandflies were reported around the Mediterranean Sea (Figure 1) in Algeria [6], Cyprus [7, 8], Egypt [9], Iran [9-11], Israel [12], Italy [13], Jordan [14] and Portugal [15]. An earlier review based on serological data, without virus isolation and characterisation, indicated that sandfly fever Sicilian or Naples viruses have been recorded in Bangladesh, Djibouti, Ethiopia, Iraq, Morocco, Saudi Arabia, Somalia, Sudan, Tunisia, southern and central Asian republics of the former Soviet Union, and the former Republic of Yugoslavia [16]. The same study showed the absence of neutralising antibodies in humans in Algeria, central Africa and eastern Asia [16].

Sandfly fevers were first described in Italy, in 19431944 during outbreaks of influenza-like illness among United States (US) soldiers due to Sicilian and Naples viruses [16]. Human cases are often found in people visiting Mediterranean countries. A total of 37 cases of sandfly fever Sicilian virus infections and one case of sandfly fever Naples virus infection were recorded in Swedish tourists returning from Cyprus between 1986 and 1989. In 1985, the incidence was low (0.3\%) among members of Swedish troops stationed in Cyprus [17]. More recently, a 2002 outbreak affecting 256 among 581 Greek soldiers stationed in Cyprus showed increasing incidence (44\%) for infections with sandfly fever Sicilian virus [8].

\section{Toscana virus infections}

Many infections with the Toscana virus are asymptomatic. Reported clinical cases mostly present with influenza-like symptoms, but the virus displays a strong neurotropism. Outbreaks of acute meningitis or meningo-encephalitis due to infections with Toscana virus have been reported in several European countries bordering the Mediterranean Sea: (Italy, France [18-25], Spain [26-30] and Portugal [31]).
Seroprevalence studies in Italy, show large variations ranging from $3 \%$ in northern Italy (Torino) [32], to $16 \%$ in Umbria [33] and $22 \%$ in central Italy. The virus is widespread in several regions including Tuscany, Piedmont, the Marches, Umbria and Emilia-Romagna.

In Spain, the seroprevalence rate is higher and ranges from $5 \%$ [27] to $26 \%$ [26]. However, the large difference in prevalence observed between the two surveys might be related to the fact that the authors did not use the same serological tests [21]. In France, the seroprevalence observed recently was $12 \%$ in a survey using blood from donors in south-eastern France [21]. In Turkey [34], a pilot study reports also positive serologies for sandfly fever Toscana, Naples and Sicilian viruses.

In Italy, from May to October, Toscana virus is a major cause of meningitis and meningo-encephalitis with a peak of incidence in August. During this period it causes $80 \%$ of cases in children and $50 \%$ of cases in adults $[32,33]$. Toscana virus is among the three most prevalent viruses associated with meningitis during the warm season. Therefore, Toscana virus must be considered as an emerging pathogen in the Mediterranean basin [19] and significant public health issue in Europe.

\section{Chandipura virus infections}

Outside of Europe, epidemics of acute encephalitis characterised by rapid onset of fever and central nervous system involvement with high case fatality rate were reported in Asia [35, 36]. These outbreaks were caused by the highly pathogenic Chandipura virus, a Vesiculovirus of the Rhabdoviridae family originally isolated in India from a patient [2]. To date, no human cases have been reported in Europe and Africa, although Chandipura virus has been isolated in Nigeria from hedgehogs (Atelerix spiculus) [37]. The fact that no human cases have been reported from there so far may reflect a lack of specific testing for Chandipura virus.

\section{FIGURE 1}

Distribution of (a) Toscana, (b) Sicilian, and (c) Naples viruses in the European Union and neighbouring countries around the Mediterranean Sea up to 2009
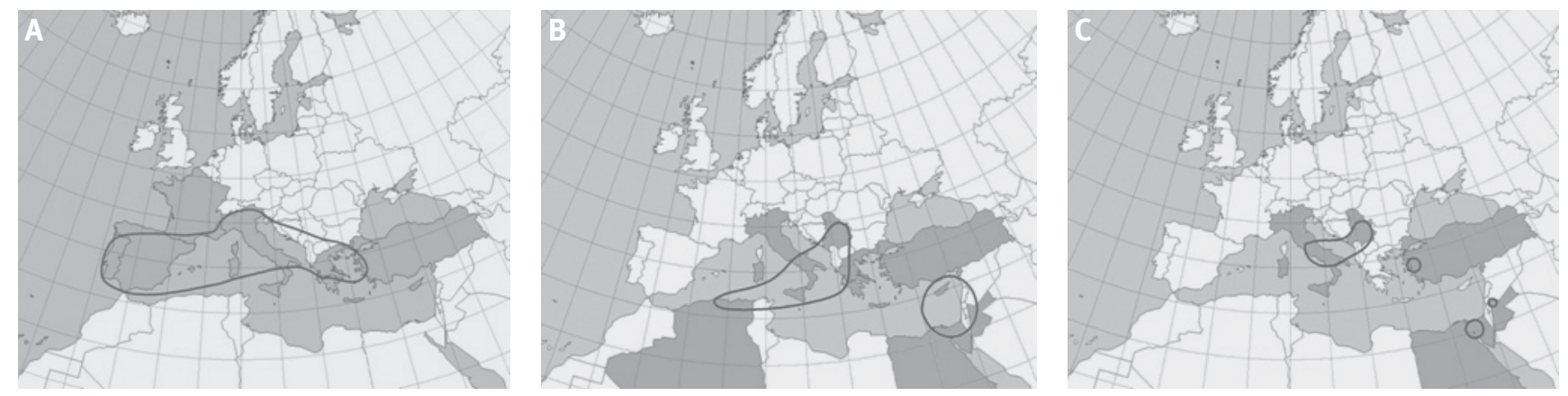

Countries with confirmed cases are depicted in mid grey, the estimated distribution limits are depicted with a dark grey line.

Source: V-borne project; reproduced with permission from the European Centre for Disease Prevention and Control. 
Among the nine species of the genus Vesiculovirus, Chandipura virus should be considered of great public health importance. Conducting surveys on Chandipura virus in the south of Europe and along the south-eastern European borders is necessary to anticipate an introduction of the virus into Europe from Asia and/or Africa.

\section{FIGURE 2}

Neighbour-joining tree based on nucleotide sequences of the large segment encoding the viral polymerase with bootstrap values (\%) calculated with 500 replicates.

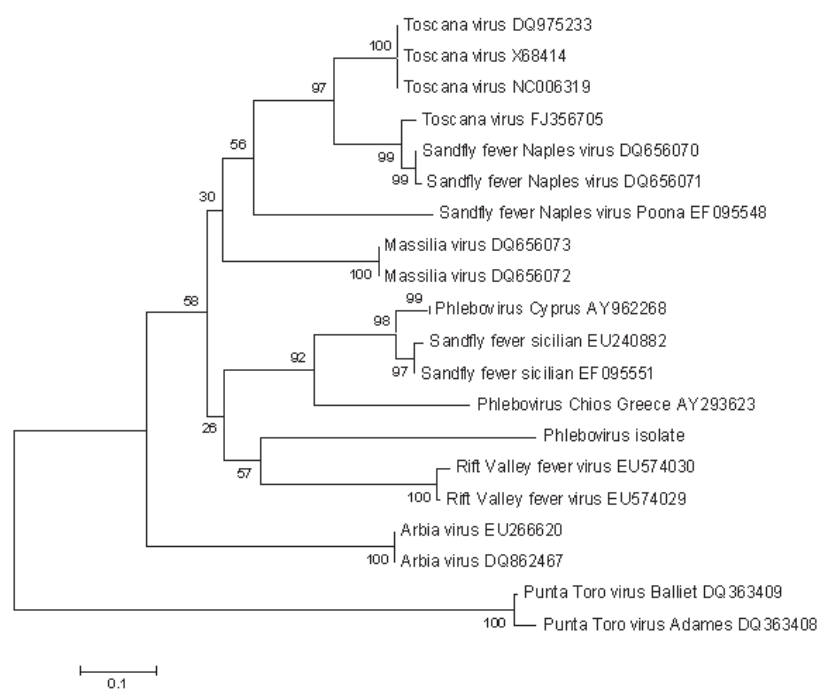

\section{Transmission}

Genus Phlebovirus

This genus contains the majority of known sandflyborne viruses. Many serotypes have been characterised in the Americas from sandflies belonging to the genera Lutzomyia sensu lato, and in Africa, Europe and Central Asia mainly from Phlebotomus and also from Sergentomyia.

According to the eighth Report of the International Committee on Taxonomy of Viruses [37], the genus Phlebovirus can be divided into nine antigenic complexes and includes 37 classified viruses. Further 16 virus serotypes are unclassified and are considered to be tentative members of the genus. Current knowledge suggests that many of the phleboviruses are maintained in their arthropod vectors by vertical (transovarial) transmission and that vertebrate hosts play little or no role in the basic maintenance cycle of these agents [1]. This maintenance mechanism has important ecological implications for the phleboviruses, as it allows them to persist during periods when adult vectors are absent or when susceptible vertebrate hosts are not available.

\section{Sandfly fever Sicilian virus}

This virus has been isolated in natura [39] and in vitro [40, 41] from $P$. papatasi captured from the Mediterranean basin to Central Asia. It has also recently been isolated in natural conditions from $P$. (L.) ariasi in Algeria [6]. In some parts of its distribution area such as Cyprus where a local strain, Cyprus virus, has been isolated from Swedish troop members [7],

\section{FIGURE 3}

Distribution of main vectors in the European Union and neighbouring countries around the Mediterranean Sea up to 2009
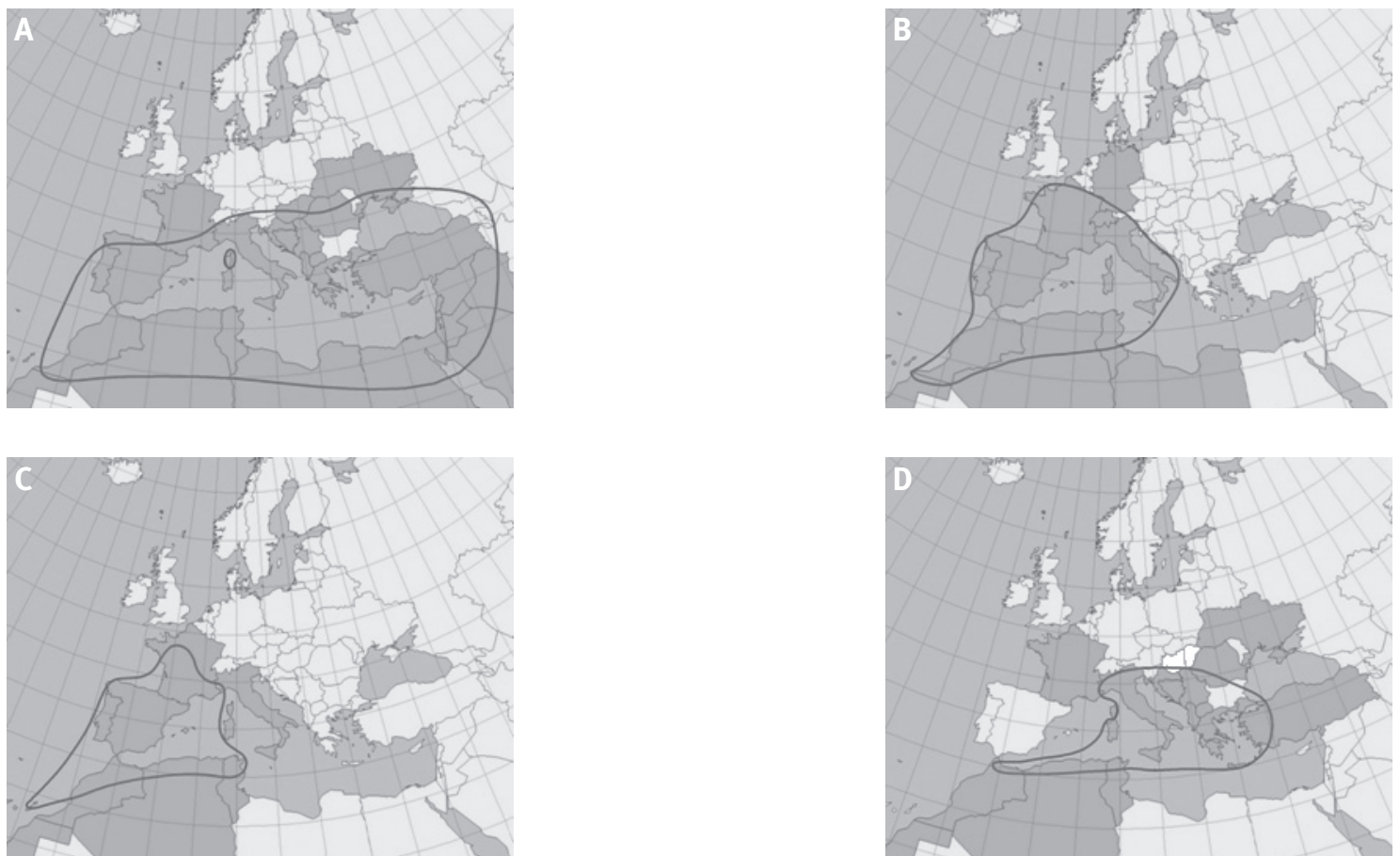

From left to right and from top to bottom: (a) Phlebotomus papatasi, (b) P. perniciosus, (c) P. ariasi, and (d) P. perfiliewi s. st. Countries with confirmed presence are depicted in mid grey, estimated distribution limits are depicted in dark grey.

Source: V-borne project; reproduced with permission from the European Centre for Disease Prevention and Control. 
$P$. papatasi is an abundant species [42] and could be a suspected vector. However, in Italy $P$. papatasi is now scarce whereas it was abundant before DDT was used in the 1940 s and cannot be a candidate for the transmission of sandfly fever Sicilian virus. Autochtonous Phlebotomus belonging to the subgenus Larroussius ( $P$. perniciosus, $P$. perfiliewi and $P$. neglectus) seem to be better candidates for its transmission. In Greece, a closely related virus called Corfou virus has been isolated from $P$. (Larroussius) neglectus [4].

Different vertebrate species including rodents (Apodemus spp., Mus musculus, Rattus rattus, Clethrionomys glareolus, Meriones libycus, Gerbillus aureus), insectivora (Soricidae and Talpidae) and carnivora (Mustela nivalis) may participate to the maintenance of Sandfly Sicilian virus life cycle [43-46].

The virus is endemic in Europe and currently there are no known reasons why it would not extend over the entire distribution range of the vectors. Its further spread could follow a wider distribution of the vector and/or the reservoirs taking into account the unknown potential impact of climatic shifts on the development of the virus in the vector. Future studies will have to determine (i) the distribution and prevalence of the disease according to serological studies in the European Mediterranean region, (ii) the vector competences and capacities of local sandfly species, (iii) the temperatures required for viral replication in infected sandflies in order to evaluate the risk of development in local vectors, and field work will have to be performed in foci where human cases, infected animal reservoirs and infected sandflies occur.

\section{Sandfly fever Naples virus}

The virus has been isolated in Italy from $P$. perniciosus [47], in Serbia from P. perfiliewi [48] and in Egypt from $P$. papatasi [49]. The area in which a stable focus is recorded has been delimited to Serbia [50]. Reservoirs for Sandfly fever Naples virus are unknown. An important seroprevalence rate of $30 \%$ has been recorded in Jordan [14]. Because the identity of the virus cannot be assessed with certainty, the virus could circulate in Turkey [51]. Future investigations similar to those developed for Toscana virus need to be carried out to gain better understanding of the potential spread of the virus.

\section{Toscana virus}

The distribution of Toscana virus includes Spain, France, Italy, Greece, Cyprus [19], Portugal [30], and Turkey [38] and it has been isolated several times from $P$. perniciosus and $P$. perfiliewi belonging to the subgenus Larroussius. Transovarial transmission has been demonstrated in laboratory conditions and by viral isolation from male Phlebotomus spp. Venereal transmission from infected males to uninfected females has also been demonstrated [52]. It is suggested that the reservoir of Toscana virus is most likely the vector itself. However, a progressive decline of vector infected rates from generation to generation, suggests that this virus cannot be maintained indefinitely by vertical transmission [53-55]. Consequently, the existence of reservoirs has to be considered. Serological data have shown no evidence of infection among domestic or wild animals. However, a Toscana virus strain was isolated from the brain of the bat Pipistrellus kuhli [56]. The viral genome detection of Toscana virus in Sergentomyia minuta [57], a species considered as feeding exclusively on lizards and geckos, points towards the possible existence of unknown reservoirs. The short duration of viraemia, and the lack of evidence for a persistent infection in humans, compromises the participation of humans in the maintenance of the virus.

The geographical extension potential of Toscana virus is high in Europe. At this time numbers of endemic foci of the virus have been identified in different neighbouring countries (Spain, France, Italy) and potential vectors are widely dispersed. However, a rapid spreading of the virus is unlikely due to the lack of evidence of animal reservoir. Humans may favour viral transportation but the shortness of viraemia may limit an efficient transmission to naïve vectors. Moreover, the potential impact of climatic shifts on the vector competence is unknown. Similarly as for the two viruses mentioned above, future studies - both field work and experimental - will have to determine the distribution and prevalence of the disease caused by Toscana virus based on serological investigations around the European Mediterranean region, the vector competences and capacities of local sandfly species (in particular $P$. ariasi and $P$. perniciosus), the temperatures required for viral replication in infected sandflies and the possible impact of climate change on the potential spread in Europe.

\section{Massilia virus, phlebovirus isolate and Punta Toro virus}

The recent isolation of Massilia virus - a new Phlebovirus - from P. (L.) perniciosus in south-eastern France [5], emphasised the necessity of performing field studies to anticipate the possible eruption in humans of this new virus. Furthermore, the isolation of a probable new Phlebovirus from a sandfly (Figure 2) in southern France during the summer 2007 increases the number of phleboviruses and the potential pathogens for humans. This highlights the need to carry out new investigations in Europe taking into account the variability of phleboviruses [58].

The distribution area of Punta Toro virus is limited to Central America where it is transmitted by Lutzomyia (Nyssomyia) trapidoi and L. (Ny.) ylephiletor. The taxonomic status of these vectors has to be clarified in the light of an entomological revision. Even if the subgenus Nyssomyia has never been recorded in the West Indies, some species belonging to it have been recorded in French Guyana such as L. anduzei, L. flaviscutellata, L. umbratilis, L. yuilli pajoti [59]. These sandfly species could be considered as possible candidates for 
native transmission in the overseas territories of the European Union (EU) which are important leisure destinations during local dry seasons. Whereas importation of Punta Toro virus in European countries is unlikely, the possible emergence of the virus will highlight the importance to have the capacity to diagnose etiologically any imported febrile syndromes in tourists returning from these areas.

The main natural Phlebotomus vectors seem to belong to the subgenus Larroussius. The vectors of the main phleboviruses in the eastern part of the Mediterranean basin are not known: in Turkey, $P$. perniciosus and $P$. ariasi are not recorded (figure 3). However, it appears difficult to assess a co-evolution between viruses and sandflies within the subgenus Larroussius: the isolation of viruses (or viral RNA) in P. papatasi or in Sergentomyia spp. strongly suggests the capture of the viruses by Phlebotomine sandflies.

\section{Genus Vesiculovirus}

\section{Chandipura virus}

Under laboratory conditions, $P$. papatasi is an efficient reservoir for the virus, showing growth, and venereal and transovarial transmission [60, 61]. The experimental transmission of Chandipura virus by $P$. (Euphlebotomus) argentipes has been recently demonstrated [62]. In natural conditions, it has been isolated from a pool of 253 unidentified Phlebotomine sandflies (Phlebotomus spp.) in the Maharashtra State of India [63] and from unidentified Sergentomyia in the Karimnagar district in Andhra Pradesh, India [64]. Four strains have also been isolated from batches of sandflies from Senegal, belonging probably to the genus Sergentomyia $[65,66]$. These data show a wide distribution of the virus and the capacity of two genera of sandflies namely Phlebotomus (subgenera Phlebotomus and Euphlebotomus) and Sergentomyia to transmit the virus.

Chandipura virus is currently endemic only in India and its introduction to Europe by an infected Phlebotomine sandfly is unlikely to occur, due to the fact that no settlement of Phlebotomine Chandipura virus vector has been documented yet. However, the importation of Chandipura virus through an infected individual with or without clinical symptoms cannot be excluded. This could be the main risk of introduction in European areas where $P$. papatasi is an abundant species. To assess the transmission risk, it is necessary to carry out studies on the duration of the viraemia in infected humans and the vector competence of autochtonous Phlebotomine species in European countries where $P$. papatasi is scarce or not recorded. The recent introduction in Cyprus of Leishmania donovani, an Asiatic and African parasite transmitted by local Phlebotomine sandflies highlights the risk of introduction diseases potentially transmitted by European Phlebotomine sandflies [67-69].
The virus Isfahan has been isolated only in Iran in $P$. papatasi, rodents and patients [70]. The Jug Bogdanovac virus has been isolated in $P$. (L.) perfiliewi in Serbia [71].

\section{Genus Orbivirus}

Orbiviruses transmitted by sandfly bites are restricted to the 12 species from the Americas belonging to the Changuinola virus group. Human infection caused by this group is not well documented and until now has presented with mild influenza-like symptoms and does not show major clinical importance [72].

\section{Laboratory diagnosis}

Direct viral diagnosis, such as isolation, RT-PCR, in blood or cerebrospinal fluid is only possible in early stages of infection i.e. the first two days after symptom onset and before the IgM sero-conversion. In most cases the diagnosis is based on serological investigation of acute and early convalescent sera. In-house enzyme-linked immunosorbent assay (ELISA) methods (MAC-ELISA and IgG sandwich) are developed in reference laboratories. To date, only one commercial kit is registered in Italy for Toscana virus diagnosis. Serological cross reactions exist within the sandfly fever Naples virus and sandfly fever Sicilian virus antigenic complex. Seroneutralisation assays using early convalescent sera remain the reference method to specifically identify the viruses or to assess the antibody response specificity. Reference tools, reagents and quality control are not widely available. However, the collaborative working group of the European Network for the diagnosis of imported viral diseases (ENIVD www.enivd.de/index.htm) is able to provide some of these reagents.

\section{Treatment and prevention}

The treatment of phlebovirus infections is symptomatic. Treatment with hepatotoxic medication as well as aspirin and other NSAIDs such as ibuprofen and ketoprofen are not recommended.

No human vaccine against Phlebotomus-borne virus is available. The prevention of phlebovirus infection relies on the control of vector proliferation in limited areas where people are highly exposed. Individual protective measures such as insect repellents and insecticide impregnated mosquito bednets are recommended in these areas.

In most cases, phlebovirus infections are self-resolving pathologies. Only two complicated forms of Toscana virus infections have been reported in the literature. If a vaccine were available, the implementation of mass vaccination programmes would not seem to be relevant for the prevention for sandfly fever Naples and sandfly fever Sicilian viruses.

\section{Risk for the future}

Data on vertebrate reservoirs is sparse for sandfly fever viruses. The factor currently known to limit the 
spread of diseases is the distribution areas of potential vectors. The distribution areas of the disease may not be restricted to the areas where they have been recorded but could be as wide as those of their vectors, that is to say Larroussius and P. papatasi mainly but not exclusively (figure 3). Consequently, field work in form of viral isolation from sandflies and possible reservoirs as well as laboratory work to establish vectorial competence of colonised sandflies need to be encouraged in a near future for three main reasons:(i) phleboviruses already endemic in the southern part of Europe have a potential to spread to other areas where their vectors are circulating, (ii) new phleboviruses of unknown pathogenicity such as the Massilia virus, that circulate among Phlebotomine sandflies may emerge in humans, (iii) the highly pathogenic Chandipura virus is paradigmatic of arthropod-borne viruses transmitted by Phlebotomine sandflies that may be introduced to Europe. At the present time, Rift Valley Fever virus has not been isolated from Phlebotomine sandflies under natural conditions. However, sandfly infections have been demonstrated under laboratory conditions for P. (P.) papatasi, P. (P.) duboscqi, P. (Paraphlebotomus) sergenti, Sergentomyia schwetzi and Lutzomyia longipalpis [73-75]. A vector competence has been demonstrated after oral infection for $P$. papatasi and P. duboscai whereas P. sergenti, S. schwetzi and L. longipalpis do not seem to be able to transmit Rift Valley Fever virus after oral infection [73-75]. The lack of isolates of Rift Valley Fever virus from field-collected Phlebotomine sandflies may could be a consequence of the low rates of capture of sandflies in arthropod field collections for virus isolation assays. Their geographical range coinciding with that of Rift Valley Fever virus in sub-Saharan Africa, and nearly all known phleboviruses seem primarily associated with sandflies. Thus, additional studies are needed to evaluate the role of sandflies as maintenance and epizootic vectors for Rift Valley Fever virus [75]. An epidemiological surveillance is also required in the EU.

\section{Phleboviruses as a potential \\ means of biological warfare}

Efficient arboviruses transmission mainly depends on vectors. Except for RVFV, no other way of Phlebovirus transmission has been reported. Breeding of Phlebotomine species and artificial infection difficulties are limiting factors for the use of phleboviruses as efficient biological weapons. Moreover, most phleboviruses are associated with asymptomatic or mild self-resolving infections in humans. Direct inter-human transmission has never been demonstrated. These criteria make phleboviruses bad candidates for the development of biological weapons.

Phleboviruses are characterised by their tripartite RNA genome. Genetic exchanges between phleboviruses are possible with unpredictable effects. Compared to RVFV, only less pathogenic phleboviruses have been identified so far. The possible genesis of a new, highly virulent Phlebovirus by this genetic-exchange mechanism seems unlikely.
Acknowledgements

This review is based on an extensive literature study conducted as part of the European Centre for Disease Prevention and Control funded V-borne project "Assessment of the magnitude and impact of vector-borne diseases in Europe", tender $\mathrm{n}^{\circ}$ 0J/2007/04/13-PROC/2007/003.

\section{References}

1. Tesh RB. The genus Phlebovirus and its vectors. Annu Rev Entomol. 1988;33:169-81.

2. Bhatt PN, Rodrigues FM. Chandipura virus: a new arbovirus isolated in India from patient with febrile illness. Indian J Med Res. 1967;55:1295-305.

3. Dhanda V, Rodriges FM, Ghosh SN. Isolation of Chandipura virus from sandflies in Aurangabad. Indian J Med Res. 1970;58(2):179-80.

4. Rodhain F, Madulo-Leblond G, Hannoun C, Tesh RB. Le virus Corfou. Un nouveau Phlebovirus virus isolé de Phlébotomes en Grèce. Ann. Insl. Pasteur/Virol. 126E 161-166, 1985. [French].

5. Charrel RN, Moureau G, Temmam S, Izri A, Marty P, Parola P, et al. Massilia virus, a novel Phlebovirus (Bunyaviridae) isolated from sandflies in the Mediterranean. Vector Borne Zoonotic Dis. 2009;9(5):519-30

6. Izri A, Temmam S, Moureau G, Hamrioui B, de Lamballerie X, Charrel RN. Sandfly fever Sicilian virus, Algeria. Emerg Infect Dis. 2008;14(5):795-7.

7. Papa A, Konstantinou G, Pavlidou V, Antoniadis A. Sandfly fever virus outbreak in Cyprus. Clin Microbiol Infect 2006;12(2):192-4.

8. 8. Konstantinou GN, Papa A, Antoniadis A. Sandfly-fever outbreak in Cyprus: are phleboviruses still a health problem? Travel Med Infect Dis. 2007;5(4):239-42.

9. Darwish MA, Feinsod FM, Scott RM, Ksiazek TG, Botros BA, Farrag IH, et al. Arboviral causes of non-specific fever and myalgia in a fever hospital patient population in Cairo, Egypt. Trans R Soc Trop Med Hyg. 1987;81(6):1001-3.

10. Saidi S, Tesh R, Javadian E, Sahabi Z, Nadim A. Studies on the epidemiology of sandfly fever in Iran. II. The prevalence of human and animal infection with five Phlebotomus fever virus serotypes in Isfahan province. Am J Trop Med Hyg. 1977;26(2):288-93.

11. Mehrabi Tavana A. The seroepidemiological studies of sandfly fever in Iran during imposed war Iran. J Public Health. 2001;30(3-4):145-6.

12. Cohen D, Zaide Y, Karasenty E, Schwarz M, LeDuc JW, Slepon R, et al. Prevalence of antibodies to West Nile fever, sandfly fever Sicilian, and sandfly fever Naples viruses in healthy adults in Israel. Public Health Rev. 1999;27(1-3):217-30.

13. Dionisio D. Esperti F, Vivarelli A, Valassina M. Epidemiological, clinical and laboratory aspects of sandfly fever. Curr Opin Infect Dis. 2003;16(5):383-8.

14. Batieha A, Saliba EK, Graham R, Mohareb E, Hijazi Y, Wijeyaratne P. Seroprevalence of West Nile, Rift Valley, and sandfly arboviruses in Hashimiah, Jordan. Emerg Infect Dis. 2000;6(4):358-62.

15. Filipe AR. Serological survey for antibodies to arboviruses in the human population of Portugal. Trans R Soc Trop Med Hyg. 1974;68(4):311-5.

16. Tesh RB, Saidi S, Gajdamovic SJ, Rodhain F, Vesenjak-Hirjan J. Serological studies on the epidemiology of sandfly fever in the Old World. Bull World Health Organ 1976;54(6):663-74.

17. Eitrem R, Vene S, Niklasson B. Incidence of sandfly fever among Swedish United Nations soldiers on Cyprus during 1985. Am J Trop Med Hyg 1990;43(2):207-11.

18. Charrel RN, Izri A, Temmam S, Delaunay P, Toga I, Dumon H, et al. Cocirculation of 2 genotypes of Toscana virus, southeastern France. Emerg Infect Dis. 2007;13(3):465-8.

19. Charrel RN, Gallian P, Navarro-Mari JM, Nicoletti L, Papa A, Sánchez-Seco MP, et al. Emergence of Toscana virus in Europe. Emerg Infect Dis. 2005;11(11):1657-63.

20. Peyrefitte CN, Devetakov I, Pastorino B, Villeneuve L, Bessaud $M$, Stolidi $P$, et al. Toscana virus and acute meningitis, France. Emerg Infect Dis. 2005;11(5):778-80.

21. De Lamballerie X, Tolou H, Durand JP, Charrel RN. Prevalence of Toscana virus antibodies in volunteer blood donors and patients with central nervous system infections in southeastern France. Vector Borne Zoonotic Dis. 2007;7(2): 275-7. 
22. Hemmersbach-Miller M, Parola P, Charrel RN, Paul Durand J, Brouqui P. Sandfly fever due to Toscana virus: an emerging infection in southern France. Eur J Int Med. 2004;15(5):316-7.

23. Dionisio D, Valassina M, Cuifolini MG, Vivarelli A, Esperti F, Cusi MG, et al. Encephalitis without meningitis due to sandfly fever virus serotype Toscana. Clin Infect Dis. 2001;32(8):1241-3.

24. Di Nicuolo G, Pagliano P, Battisti S, Starace M, Mininni V, Attanasio, et al. Toscana virus central system infection in southern Italy. J Clin Microbiol. 2005;43(12):6186-8.

25. Valassina M, Meacci F, Valensin PE, Cusi MG. Detection of neurotropic viruses circulating in Tuscany: the incisive role of Toscana virus. J Med Virol. 2003;60(1):86-90.

26. Mendoza-Montero J, Gámez-Rueda MI, Navarro-Marí JM, de la Rosa-Fraile M, Oyonarte-Gómez S. Infections due to sandfly fever virus serotype Toscana in Spain. Clin Infect Dis. 1998;27(3):434-6.

27. Echevarria JM, de Ory F, Guisasola ME, Sanchez-Seco MP, Tenorio A, Lozano A, et al. Acute meningitis due to Toscana virus infection among patients from both the Spanish Mediterranean region and the region of Madrid. J Clin Virol. 2003;26(1):79-84.

28. Navarro JM, Fernández-Roldán C, Pérez-Ruiz M, Sanbonmatsu S, de la Rosa M, Sánchez-Seco MP. [Meningitis by Toscana virus in Spain: clinical description of 17 cases]. Med Clin (Barc). 2004;122(11):420-2. [Spanish]

29. Sanbonmatsu-Gámez S, Pérez-Ruiz M, Palop-Borrás B, Navarro-Marí JM. Unusual manifestation of Toscana virus infection, Spain. Emerg Infect Dis. 2009;15(2):347-8.

30. Sanbonmatsu-Gámez S, Pérez-Ruiz M, Collao X, Sánchez-Seco MP, Morillas-Márquez F, de la Rosa-Fraile M, et al. Toscana virus in Spain. Emerg Infect Dis. 2005;11(11):1701-7.

31. Santos L, Simões J, Costa R, Martins S, Lecour H. Toscana virus meningitis in Portugal, 2002-2005. Euro Surveill. 2007;12(6). pii=715. Available from: http://www.eurosurveillance.org/ ViewArticle.aspx?Articleld $=715$

32. Pugliese A, Beltramo T, Torre D. Seroprevalence study of Tickborne encephalitis, Borrelia burgdorferi, Dengue and Toscana virus in Turin Province. Cell Biochem Funct. 2007;25(2):185-8.

33. Francisci D, Papili R, Camanni G, Morosi S, Ferracchiato N, Valente $M$, et al. Evidence of Toscana virus circulation in Umbria: first report. Eur J Epidemiol. 2003;18(5):457-9.

34. Ozbel Y, Ertabaklar H, Ciufolini MG, Marchi A, Fiarentino C, Erensoy S, et al. A neglected vector-borne disease: papatas fever and its vectors in Turkey. ISOPS $V$ th International Symposium on Phlebotomine Sandflies Tunis, 17-21 April, 2005. Arch Inst Pasteur Tunis. 2005;82: 55-56.

35. Tandale BV, Tikute SS, Arankalle VA, Sathe PS, Joshi MV, Ranadive SN, et al. Chandipura virus: a major cause of acute encephalitis in children in North Telangana, Andhra Pradesh, India. J Med Virol. 2008;80(1):118-24.

36. Rao BL, Basu A, Wairagkar NS, Gore MM, Arankalle VA, Thakare JP, et al. A large outbreak of acute encephalitis with high fatality rate in children in Andhra Pradesh, India, in 2003, associated with Chandipura virus. Lancet. 2004;364(9437):869-74.

37. Kemp GE. Viruses other than arenaviruses from West African wild mammals. Bull World health Organ. 1975;52(4-6):615-20.

38. Nichol ST, Beaty BJ, Elliott RM, Goldbach R, Plyusnin A, Schmaljohn CS, et al. Genus Phlebovirus. Fauguet CM, Mayo MA, Maniloff J, Desselberger U, Ball LA, editors. In Virus Taxonomy: Eighth Report of the International Committee on Taxonomy of Viruses, pp. 709-711. San Diego, CA: Elsevier Academic Press, 2005.

39. Tesh R, Saidi S, Javadian E, Nadim A. Studies on the epidemiology of sandfly fever in Iran. I. Virus isolates obtained from Phlebotomus. Am J Trop Med Hyg. 1977;26(2):282-7.

40. Jennings $M$, Boorman J. Laboratory infection of the sandfly Phlebotomus papatasi Scopoli (Diptera, Psychodidae) with three Phleboviruses. Trans R Soc Trop Med Hyg. 1983;77(1):62-4

41. Watts DM, MacDonald C, Bailey CL, Meegan JM, Peters CJ, McKee KT Jr. Experimental infection of Phlebotomus papatasi with sand fly fever Sicilian virus. Am J Trop Med Hyg. 1988;39(6):611-6

42. Depaquit J, Léger N, Ferté H, Rioux JA, Gantier JC, Michaelides A, Economides P. [Phlebotomines of the Island of Cyprus. III. Species inventory]. Parasite. 2001;8(1):11-20. [French].

43. Chastel C, Bach-Hamba D, Launay H, Le Lay G, Hellal H, Beaucournu JC. Arbovirus infections in Tunisia: new serological survey of small wild mammals]. Bull Soc Path Exot Filiales. 1983;76(1):21-33. [French].
44. Chastel C, Launay H, Bailly-Choumara H, Le Lay G, Beaucournu JC. [Arbovirus infections in Morocco: serosurvey in small wild mammals in the northern part of the country]. Bull. Soc Path Exot Filiales. 1982;75(5):466-75. [French].

45. Chastel C, Launay H, Rogues G, Beaucournu JC. [Arbovirus infections in Spain: serological survey on small mammals]. Bull Soc Path Exot Filiales. 1980;73(4):384-90. [French].

46. Le Lay Roguès G, Valle $M$, Chastel C, Beaucournu JC. [Small wild mammals and arboviruses in Italy]. Bull Soc Path Exot Filiales. 1983;76(4):333-45. [French].

47. Verani P, Lopes MC, Nicoletti L, Balducci M. Studies on Phlebotomus-transmitted viruses in Italy: I. Isolation and characterization of a Sandfly fever Naples-like virus. Arboviruses in the Mediterranean Countries, Zbl. Bakt. Suppl. 9, Gustav Fischer Verlag. Stuttgart-New York, 195-201, 1980.

48. Gligic A, Miscevic Z, Tesh RB, Travassos da Rosa A, Zivkovic V. First isolation of Naples sandfly fever in Yugoslavia. Acta Biol Jug Mikrobiol. 1982;19:167-75.

49. Schmidt JR, Schmidt ML, Said MI. Phlebotomus fever in Egypt. Isolation of Phlebotomus fever viruses from Phlebotomus papatasi. Am J Trop Med Hyg. 1971;20(3):483-90.

50. Vesenjak-Hirjan J, Punda-Polić V, Dobe M. Geographical distribution of arboviruses in Yugoslavia. J Hyg Epidemiol Microbiol Immunol. 1991;35(2):129-40.

51. Becker M, Zielen S, Schwarz TF, Linde R, Hofmann D. [Pappataci fever]. Klin Padiatr 1997;209(6):377-9. [German].

52. Tesh RB, Lubroth J, Guzman H. Simulation of arbovirus overwintering: survival of Toscana virus (Bunyaviridae: Phlebovirus) in its natural sand fly vector Phlebotomus perniciosus. Am J Trop Med Hyg. 1992;47(5):574-81.

53. Tesh RB, Modi GB. Maintenance of Toscana virus in Phlebotomus perniciosus by vertical transmission. Am J Trop Med Hyg 1987;36(1):189-93.

54. Ciufolini MG, Maroli M, Guandalini E, Marchi A, Verani P. Experimental studies on the maintenance of Toscana and Arbia viruses (Bunyaviridae:Phlebovirus). Am J Trop Med Hyg. 1989;40(6):669-75.

55. Ciufolini MG, Maroli M, Verani P. Growth of two phleboviruses after experimental infection of their suspected sand fly vector, Phlebotomus perniciosus (Diptera:Psychodidae). Am J Trop Med Hyg. 1985;34(1):174-9.

56. Verani P, Ciufolini MG, Caciolli S, Renzi A, Nicoletti L, Sabatinelli G, et al. Ecology of viruses isolated from sand flies in Italy and characterization of a new Phlebovirus (Arbia virus). Am J Trop Med Hyg. 1988;38(2):433-9.

57. Charrel RN, Izri A, Temmam S, de Lamballerie X, Parola P. Toscana virus RNA in Sergentomyia minuta flies. Emerg Infect Dis. 2006;12(8):1299-300.

58. Valentini M, Valassina M, Savellini GG, Cusi MG. Nucleotide variability of Toscana virus $M$ segment in strains isolated from clinical cases. Virus Res. 2008;135(1):187-90.

59. Fouque F, Gaborit P, Issaly J, Carinci R, Gantier JC, Ravel C, et al. Phlebotomine sand flies (Diptera: Psychodidae) associated with changing patterns in the transmission of the human cutaneous leishmaniasis in French Guiana. Mem Inst Oswaldo Cruz. 2007;102(1):35-40.

6o. Tesh RB, Modi GB. Growth and transovarial transmission of Chandipura virus (Rhabdoviridae: Vesiculovirus) in Phlebotomus papatasi. Am J Trop Med Hyg. 1983;32(3):621-3.

61. Mavale MS, Fulmali PV, Geevarghese G, Arankalle VA, Ghodke YS, Kanojia PC, et al. Venereal transmission of Chandipura virus by Phlebotomus papatasi (Scopoli). Am J Trop Med Hyg. 2006;75(6):1151-2.

62. Mavale MS, Fulmali PV, Ghodke YS, Mishra AC, Kanojia P, Geevarghese $G$. Experimental transmission of Chandipura virus by Phlebotomus argentipes (Diptera:Psychodidae). Am J Trop Med Hyg. 2007;76(2):307-9.

63. Dhanda V, Rodrigues FM, Ghosh SN. Isolation of Chandipura virus from sandflies in Aurangabad. Indian J Med Res. 1970;58(2):179-80.

64. Geevarghese G, Arankalle VA, Jadi R, Kanojia PC, Joshi MV, Mishra AC. Detection of chandipura virus from sand flies in the genus Sergentomyia (Diptera: Phlebotomidae) at Karimnagar District, Andhra Pradesh, Indian J Med Entomol. 2005;42(3):495-6.

65. Ba Y, Trouillet J, Thonnon J, Fontenille D. [Phlebotomus of Senegal: survey of the fauna in the region of Kedougou. Isolation of arbovirus]. Bull Soc Pathol Exot. 1999;92(2):131-5 [French].

66. Fontenille D, Traore-Lamizana M, Trouillet J, Leclerc A, Mondo M, Ba Y, et al. First isolations of arboviruses from Phlebotomine sand flies in West Africa. Am J Trop Med Hyg. 1974;50(5):570-4. 
67. Antoniou M, Haralambous C, Mazeris A, Pratlong F, Dedet JP, Soteriadou K. Leishmania donovani leishmaniasis in Cyprus. Lancet Infect Dis. 2008;8(1):6-7.

68. Antoniou M, Haralambous C, Mazeris A, Pratlong F, Dedet JP, Soteriadou K. Leishmania donovani leishmaniasis in Cyprus. Lancet Infect Dis. 2009;9(2):76-7.

69. Léger N, Depaquit J. Leishmania donovani leishmaniasis in Cyprus. Lancet Infect Dis. 2008;8(7):402.

70. Tesh R, Saidi S, Javadian E, Loh P, Nadim A. Isfahan virus, a new Vesiculovirus infecting humans, gerbils, and sandflies in Iran. Am J Trop Med Hyg. 1977;26(2):299-306.

71. Gligic A, Tesh RB, Miscevic Z, Travassos da Rosa A, Zivkovic V. Jug Bogdanovac virus - A new of the vesicular virus serogroup (Rhabdoviridae:Vesiculovirus) isolated from Phlebotomine sandflies in Yugoslavia. Acta Biol Jug Mikrobiol. 1983;20:97-105

72. Polly R. Orbiviruses. In: Fields Virology, 5’ Edn. 2007 (D.M. Knipe and P. Howley, eds), pp 1975-1997. Lippincott, Williams and Wilkins, Philadelphia.

73. Dohm DJ, Rowton E, Lawyer PG, O’Guinn M, Turell MJ. Laboratory Transmission of Rift Valley Fever Virus by Phlebotomus duboscqi, Phlebotomus papatasi, Phlebotomus sergenti, and Sergentomyia schwetzi (Diptera:Psychodidae). Med Entomol. 2000;37(3):435-8.

74. Hoch AL, Turell MJ, Bailey CL. Replication of Rift Valley fever virus in the sand fly Lutzomyia longipalpis. Am J Trop Med Hyg. 1984;33(2):295-9.

75. Turell MJ, Perkins PV. Transmission of Rift Valley fever virus by the sand fly Phlebotomus duboscqi (Diptera: Psychodidae). Am J Trop Med Hyg. 1990;42(2):185-8. 